\title{
Single-Phase to Three-Phase Unified Power Quality Conditioner for Power Factor Improvement Using Fuzzy Logic Controller
}

\author{
Thumuganti Ramya ${ }^{1} \mid$ Dhavala Pranusha ${ }^{1}$ \\ ${ }^{1}$ Assistant Professor, Department of EEE, Vignan Institute of Technology and Science, Hyderabad, Telangana, India.
}

To Cite this Article

Thumuganti Ramya and Dhavala Pranusha, "Single-Phase to Three-Phase Unified Power Quality Conditioner for Power Factor Improvement Using Fuzzy Logic Controller", International Journal for Modern Trends in Science and Technology, Vol. 06, Issue 05, May 2020, pp.:06-12; https://doi.org/10.46501/IJMTST060502

Article Info

Received on 30-March-2020, Revised on 19-April-2020, Accepted on 23-April-2020, Published on 28-April-2020.

\section{ABSTRACT}

This paper manages the arrangement of a nearby three stage four wire $(3 P 4 W)$ electrical power appropriation framework (EPDS), utilizing a solitary to three stage bound together power quality conditioner (UPQC) topology with fluffy controller, called UPQC 1Ph to 3Ph. The topology is shown for applications in country or remote zones in which, for financial reasons, just EPDS with single wire earth return are open to the buyer. Since the utilization of three stage loads is expanding in these regions, access to a three stage dispersion framework ends up dominant. By embracing a double pay methodology, the proposed UPQC 1Ph to $3 P h$ is capable of depleting from the single stage electrical framework a sinusoidal flow and in stage with the voltage, coming about high power factor. Moreover, the framework is likewise ready to stifle lattice voltage sounds, just as to make up for different aggravations, for example, voltage lists. In this proposed topology we are utilizing fluffy rationale controller to Single-Phase To Three-Phase Unified Power Quality Conditioner to decrease of the music and execution will be expanded. Along these lines, a 3P4W framework with fluffy managed, offset and sinusoidal voltages with low consonant substance is accommodated single and three stage loads. An examination of the power move through the arrangement and parallel converters is performed so as to help the structuring of the power converters. Reenactment results are exhibited for approving the proposition of fluffy, just as assessing the static and dynamic exhibitions of the proposed topology.

KEYWORDS: Power Quality (PQ), Unified Power Quality Conditioner (UPQC), Electrical power dissemination frameworks (EPDS).

Copyright (C) 2014-2020 International Journal for Modern Trends in Science and Technology, All rights reserved. DOI: https://doi.org/10.46501/IJMTST060502

\section{INTRODUCTION}

Electrical power dissemination frameworks (EPDS) with single-wire earth return (SWER) have been ordinarily received as an answer for electrical power providing. This is because of the way that the decrease of expenses in the conveyance of vitality to serve expansive regional augmentations with low statistic densities is an essential prerequisite, since lower establishment and support costs are achieved. Other options are the utilization of vitality dispersion by methods for two conductors (stage to neutral) without earth return 
or notwithstanding utilizing two-stage frameworks (stage to-stage). Thinking about these options, capital ventures for the acknowledgment of SWER dissemination lattice offices establishments are still lower.

Bound together power quality conditioner (UPQC) is one of the advanced types of intensity molding gadget, which is a blend of consecutive associated arrangement APF (SAPF) and shunt dynamic power channel (PAPF) appended to a typical DC connect voltage. This topology will encourages this gear to have a decreased dc-interface voltage without diminishing its pay capacity. This gadget is basically utilized in showing signs of improvement the power quality. The interest for power quality (PQ) enhancement has been growing lately, predominantly as a result of the expansion of nonlinear burdens joined to the electrical power framework causing mutilations in the utility voltages at the purpose of basic coupling [1]. These days Power quality issues have gotten an incredible consideration in light of their effects on the two utilities and clients. Brought together power quality conditioner is outstanding amongst other custom power gadget used to remunerate both source and load side issues.

$\mathrm{N}$ rustic or remote locales in Brazil, just as in a few territories of nations, for example, Australia and New Zealand, for example, electrical power dispersion frameworks (EPDS) with single-wire earth return (SWER) have been regularly embraced as an answer for electrical power providing. This is because of the way that the decrease of expenses in the circulation of vitality to serve expansive regional augmentations with low statistic densities is a vital prerequisite [1] - [5], since lower establishment and upkeep costs are accomplished [4], [6].

Different choices are the utilization of vitality circulation by methods for two conductors (stage to-impartial) without earth return, or notwithstanding utilizing two-stage frameworks (stage to-stage). Thinking about these choices, capital ventures for the acknowledgment of SWER appropriation framework offices establishments are still lower [7]. The interest for electrical vitality in single-stage rustic conveyance lattices has extensively expanded in the most recent decades, both in farming and in domesticated animals, primarily because of the expanding advancement and modernization of the innovations utilized, just as the expansion in the motorization of generation forms. It is conceivable to specify, for instance, the mechanization of water system, just as the post-collect rural preparing including seed determination and processing, ventilation and refrigeration, washing and bundling lines, among others. Inside this unique situation, there is a fast approaching pattern of expanding vitality request in country properties, just as the need to enhance control quality improvement because of the adjustment in the attributes of the heaps. The voltage direction is described as one of the fundamental issues of intensity quality (PQ) found in the provincial singlephase matrices [4], [5], in light of the fact that when exposed to substantial burdens, these frameworks have huge voltage drops, while on occasion of low utilization the voltage will in general ascent [1]. By and by, an answer not all that proficient because of steady load varieties can be received by changing the taps of the transformer of the SWER arrange. Another arrangement, progressively productive for this situation, is the utilization of single-stage voltage controllers [5]. Some approaches to sidestep extensive capital ventures to take care of the developing demand of rustic properties have been received [3], [8]. In [3] the effects caused between disseminated age frameworks actualized through photovoltaic frameworks and the SWER conveyance frameworks are displayed. Then again, in [8], the utilization of vitality stockpiling frameworks by methods for batteries and their utilization at pinnacle request is talked about. It is conceivable to see an expanding need to utilize three-stage conveyance frameworks to take care of the demand for electrical vitality in rustic territories because of changes in the qualities of the heaps. At present, the majority of them could be driven by three-stage acceptance engines rather than single-stage engines, for they have a higher beginning torque [7]. Moreover, the utilization of medium and high power three-stage voltage inverters associated with current mechanized frameworks likewise legitimizes the requirement for threephase lattices in rustic territories. In this manner, the nearness of a neighborhood three-stage vitality appropriation framework in zones that make utilization of the SWER conveyance framework turns out to be increasingly fundamental. For this reason, a few arrangements or potentially designs of single-stage to-three-stage (1Ph-to-3Ph) converters have been tended to in the writing [6], [7], [9]-[11]. These incorporate $1 \mathrm{ph}$-to-3Ph four-wire converters, which are capable of providing three-stage and single-stage loads [6], [7], [9], or $1 \mathrm{Ph}-$ to-3Ph three-wire converters expected to supply just three-stage 
loads [10], [11]. Devoted to nourish three-stage three-wire loads and incorporating the working of the brought together power quality conditioner (UPQC), the 1Ph-to-3Ph converter displayed in [12] performs widespread sifting, i.e., it works as seriesparallel dynamic power channel, in which the arrangement converter is made out of a solitary stage full-connect inverter (two inverter legs), while the parallel converter is made out of a threephase three-leg inverter, totaling five inverter legs. In [13], likewise incorporating the usefulness of an UPQC, a $1 \mathrm{Phto}-3 \mathrm{Ph}$ converter was committed for making a neighborhood threephase four-wire (3P4W) EPDS from a solitary stage dispersion framework. The arrangement converter is made out of a half-connect inverter (one inverter leg), while the parallel converter is made out of a three-leg split-capacitor inverter, totaling four inverter legs. In this way, it was permitted feed singleand three-stage loads. Then again, restricted outcomes have just been displayed by methods for recreations. Moreover, no insight about to the dimensioning and control of the converters were reasonably treated.

It is additionally seen that the exhibitions of the controllers are outstandingly better when they work with sinusoidal references, when contrasted with those that utilization non-sinusoidal references. Moreover, since the control references are sinusoidal, the controllers actualized in the synchronous reference casing will have constant reference of voltage and current, encouraging much more the control [19]. Another favorable position of double pay is as age of control references, which is performed just with the utilization of a Phase-Locked Loop (PLL) framework [20]. The principle commitment displayed in this paper is to approve tentatively the UPQC-1Ph-to-3Ph bound to bolster singleand three-stage loads from the SWER control conveyance frameworks, normally found in country or potentially remote regions and endure with $\mathrm{PQ}$ issues. By embracing the double remuneration procedure, the proposed UPQC-1Ph-to-3Ph makes conceivable to deplete from the single-stage electrical network a sinusoidal flow in stage with the matrix voltage. Moreover, the framework can likewise smother music from the network voltage, just as adjust for voltage unsettling influences, for example, voltage hangs/swell. At the end of the day, the UPQC-1Ph-to-3Ph can consider a nearby $3 \mathrm{P} 4 \mathrm{~W}$ framework with managed, adjusted and sinusoidal load voltages with low consonant substance enhancing the PQ pointers [23]. Subsequently, the proposed framework can accomplish two vital capacities at the same time, as depicted: I. convert the single-stage framework into a three-stage matrix, creating a 3P4W conveyance framework with earthed impartial wire to the last shopper, permitting to interface singleand there-stage loads; ii. play out the arrangement and parallel dynamic power sifting enhancing $\mathrm{PQ}$ pointers, for example, control factor, consonant mutilation [23]. Besides, so as to aid the correct dimensioning of the UPQC-1Ph-to-3Ph power converters, an investigation including the power course through the sequential and parallel converters is additionally displayed.

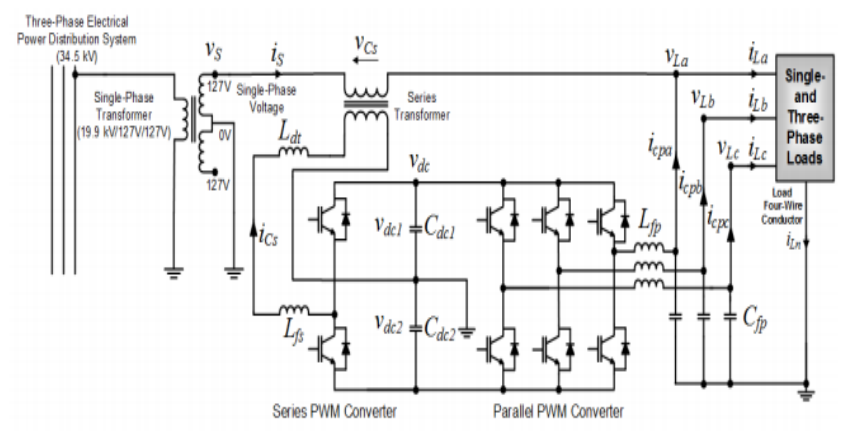

Fig1: Topology of the UPQC-1Ph-to-3Ph.

\section{PROBLEM DEFINITION}

For this reason, a few arrangements as well as setups of single-stage to-three-stage (1Ph-to-3Ph) converters have been tended to in the writing [6], [7], [9]-[11]. These incorporate 1ph-to-3Ph four-wire converters, which are capable of providing three-stage and single-stage loads [6], [7], [9], or $1 \mathrm{Ph}$-to-3Ph three-wire converters planned to supply just three-stage loads [10], [11]. Committed to sustain three-stage three-wire loads and coordinating the working of the brought together power quality conditioner (UPQC), the 1Ph-to-3Ph converter introduced in [12] performs general sifting, i.e., it works as arrangement parallel dynamic power channel, in which the arrangement converter is made out of a solitary stage full-connect inverter (two inverter legs), while the parallel converter is made out of a three stage three-leg inverter, totaling five inverter legs. In [13], additionally coordinating the usefulness of an UPQC, a 1Phto-3Ph converter was devoted for making a neighborhood three stage four-wire (3P4W) EPDS from a solitary stage appropriation framework. The arrangement converter is made out of a half-connect inverter (one inverter leg), while the parallel converter is made out of a three-leg 
split-capacitor inverter, totaling four inverter legs. Along these lines, it was permitted feed single and three-stage loads. Then again, constrained outcomes have just been introduced by methods for reenactments. Furthermore, no insight about to the dimensioning and control of the converters were appropriately treated. In this paper, the $1 \mathrm{Ph}$-to-3Ph converter displayed in [13] is tentatively approved. It is called UPQC-1Ph-to-3Ph and its capacity circuit design is appeared in Fig. 1. This framework is shown for applications in provincial or remote territories where, for financial reasons, just single-stage EPDS, for example, SWER framework, is available to the purchaser. When the proposed framework sent in this paper was imagined dependent on the UPQC functionalities, a few dialogs identified with the UPQC ought to be performed. Since they all the while play out the elements of arrangement dynamic power channel (SAPF) and parallel dynamic power channel (PAPF), the UPQCs have been regularly utilized to moderate $\mathrm{PQ}$ issues, both in single-stage appropriation frameworks [14] and in 3P4W dissemination frameworks [15]-[19]. Typically, the UPQCs are controlled to perform arrangement and parallel remuneration, combining non-sinusoidal amounts of voltage and current, i.e., the arrangement converter integrates non-sinusoidal voltage amounts to adjust for lattice voltage unsettling influences, while the parallel converter orchestrates non-sinusoidal current amounts with the reason for smothering consonant flows and repaying the receptive intensity of the heaps [15]. For this pay technique, some figuring strategy fit for producing the voltage and current pay references ought to be utilized. Then again, a few investigations introduced in the writing have utilized the double pay procedure to control the arrangement and parallel converters of the UPQC [16]-[19]. In this procedure, sinusoidal voltage and current references are utilized to control both the converters. For this situation, the arrangement converter blends sinusoidal current amounts and, therefore, works as a sinusoidal current source, giving a high impedance way to the present music of the heap. The parallel converter combines sinusoidal voltage amounts and, for this situation, works as a sinusoidal voltage source, giving a low impedance way to the present music of the heap.

\section{CONTROL REFERENCES OF SERIES \& PARALLEL CONVERTERS}

\section{A. Current Reference of the Series Converter:}

The single-stage current reference used to control the SAPF is acquired in the synchronous reference outline dq, as appeared in Fig. 2. In this way, the heap flows ( La I , Lb I , Lc I) are estimated and changed from the three-stage stationary reference outline (abc-tomahawks) to the two-stage stationary reference outline ( ) utilizing the Clarke change. At that point, by $\square 0$ tomahawks $\square \square$ methods for the Park change, the stationary current amounts of the reference outline $0 \square \square$ are changed to the synchronous reference outline (dq-tomahawks). In the pivoting outline, the directions of the unit vector $\sin (\theta)$ and $\cos (\theta)$ are acquired utilizing the PLL framework exhibited in [20], in which $\square$ is the evaluated stage edge of the matrix voltage. The amount d I, appeared in Fig. 2, speaks to the dynamic segments of the heap flows, i.e., it is made out of a normal part and wavering segments in the reference outline (d-pivot).

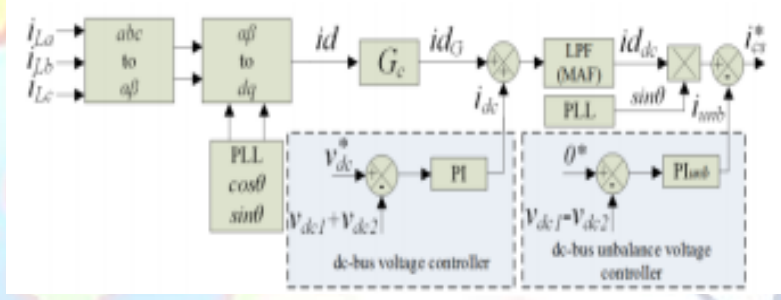

Fig2: Generation scheme of the series converter current reference the synchronous reference frame $d q$

\section{Voltage Controller of the Parallel CONVERTER}

Fig. presents, by methods for a square outline, the voltage control circles just as the normal model of the parallel converter considering just stage "a". The multi-circle control is executed by an inward current control circle, where just a relative controller is utilized, and an outside voltage control circle, in which a PI controller is utilized. In this way, from the chart of Fig. 4, the exchange capacity of the framework.

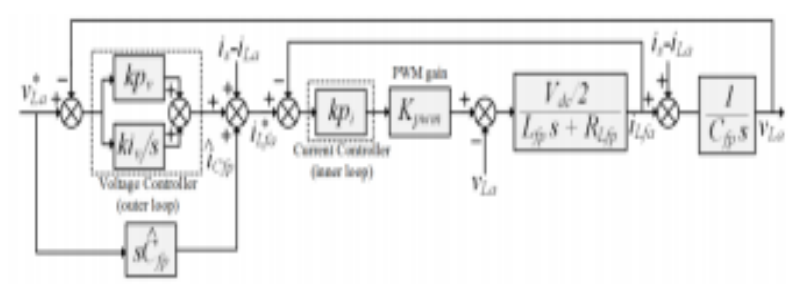

Fig3: Block diagram of the voltage control loops and of the average model of the parallel converter 

Factor Improvement Using Fuzzy Logic Controller"

\section{DC-Bus Voltage Controller}

By receiving a technique like that introduced in [22], it is conceivable to acquire the voltage control of the dc-transport chart as appeared in Fig. 6. Along these lines, the little flag shut circle exchange capacity of the dc-transport control framework.

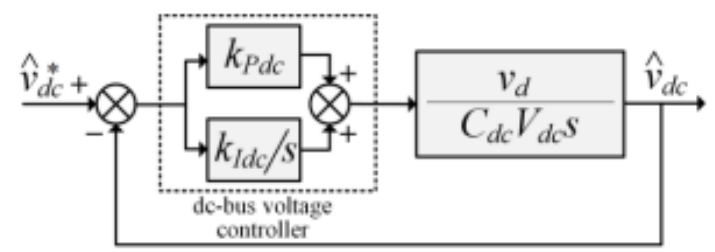

Fig4: Block diagram of the dc-bus control system.

\section{FUZZY LOGIC}

As of late, the number and assortment of utilizations of fluffy rationale have expanded altogether. The applications run from buyer items, for example, cameras, camcorders, clothes washers, and microwaves to mechanical process control, therapeutic instrumentation, choice emotionally supportive networks, and portfolio choice. To comprehend why utilization of fluffy rationale has developed, you should initially comprehend what is implied by fluffy rationale.

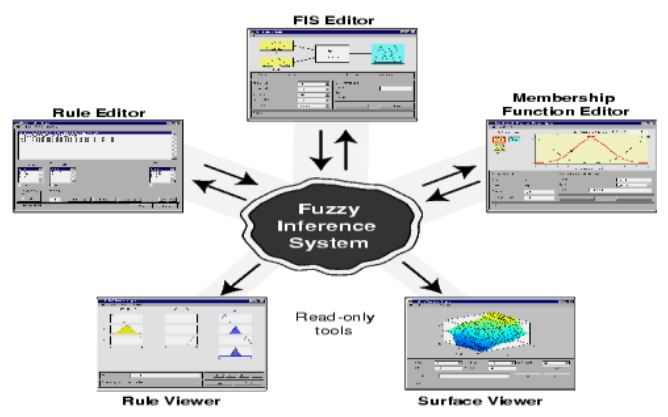

Fig. 5 The Primary GUI Tools Of The Fuzzy Logic Toolbox

The FIS Editor handles the abnormal state issues for the framework: How much info and yield factors? What are their names? The Fuzzy Logic Toolbox doesn't restrict the quantity of sources of info. In any case, the quantity of data sources might be constrained by the accessible memory of your machine. In the event that the quantity of information sources is excessively huge, or the quantity of participation capacities is too huge, at that point it might likewise be hard to examine the FIS utilizing the other GUI instruments.

The Membership Function Editor is utilized to characterize the states of all the enrollment capacities related with every factor. The Rule
Editor is for altering the rundown of principles that characterizes the conduct of the framework.

\section{THE FIS EDITOR:}

The accompanying dialog strolls you through building another fluffy surmising framework without any preparation. On the off chance that you need to spare time and track with rapidly, you can stack the effectively manufactured framework by composing fluffy tipper This will stack the FIS related with the record tipper.fis (the fis is inferred) and dispatch the FIS Editor. Be that as it may, on the off chance that you stack the pre-assembled framework, you won't manufacture leads and building enrollment capacities.

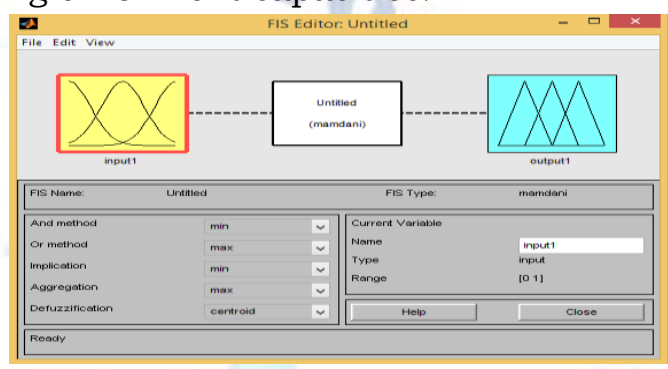

Fig6. The FIS Editor

You will see the graph refreshed to mirror the new names of the information and yield factors. There is presently another variable in the workspace considered tipper that contains all the data about this framework.

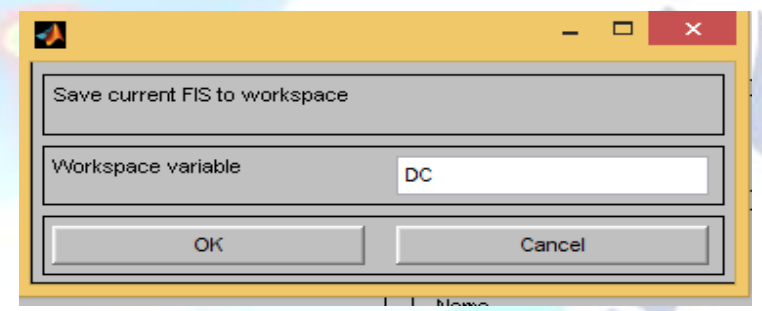

Fig7. 'Save to workspace as...' window

By saving to the workspace with a new name, you also rename the entire system. Your window will look like as shown in Fig.

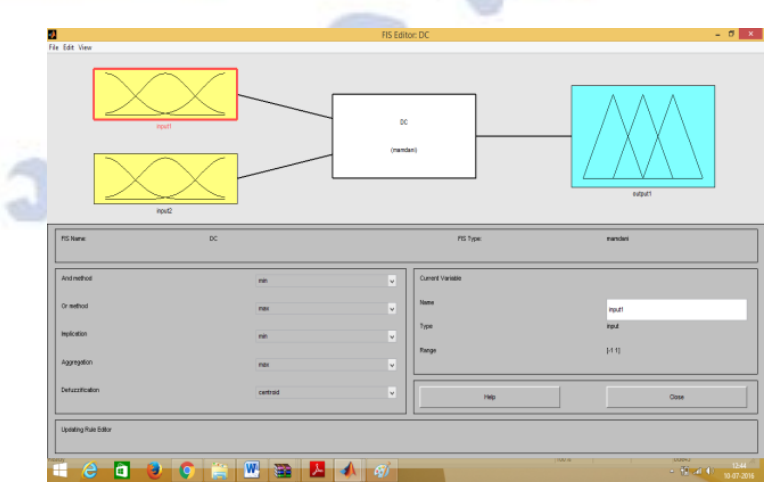

Fig8.The Updated FIS Editor 
THE MEMBERSHIP FUNCTION EDITOR:

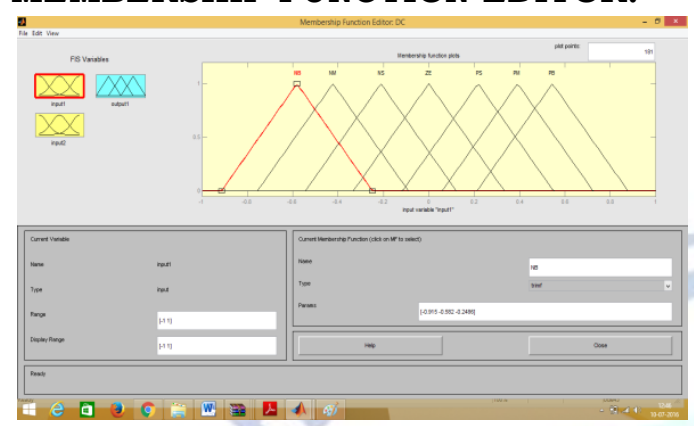

Fig9.The Membership Function Editor

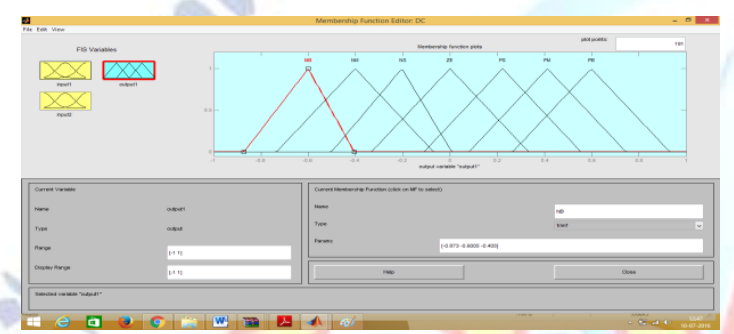

FIG10: The Updated Membership Function Editor

\section{THE RULE EDITOR:}

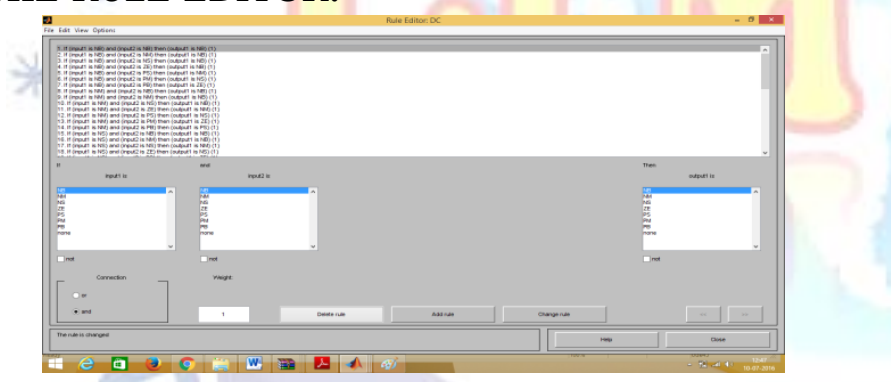

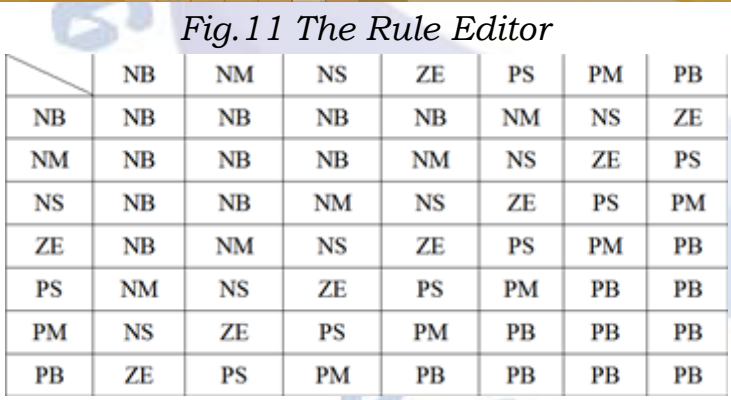

Fig12: Fuzzy rules

\section{SIMULINK MODEL}

The Simulink created by Math Works, is an information stream graphical programming dialect device for demonstrating, recreating and breaking down multi area dynamic frameworks. Its essential interface is a graphical square outlining instrument and an adjustable arrangement of square libraries. It offers tight combination with whatever is left of the MATLAB condition and can either drive MATLAB or be scripted from it. Simulink is generally utilized in charge hypothesis and computerized flag handling for multi area recreation and Model-Based Design. From the MATLAB demonstrate it was conceivable to assemble and test UPQC frameworks and to upgrade their execution before usage on the real gear. This enabled quicker advancement and the chance to examine control. With the end goal of controller configuration, show confirmation and assessment were displayed in MATLAB utilizing SIMULINK. Fig 2 demonstrates the MATLAB Simulation of Dual brought together power quality conditioner. Having arrangement and shunt dynamic power channels with IGBTs.

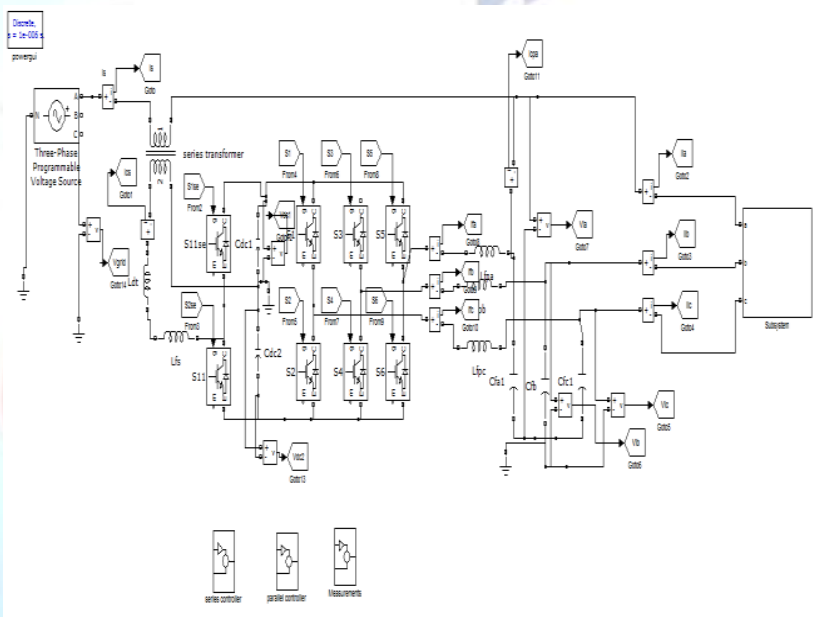

Fig. 13: Simulation of Dual UPQC

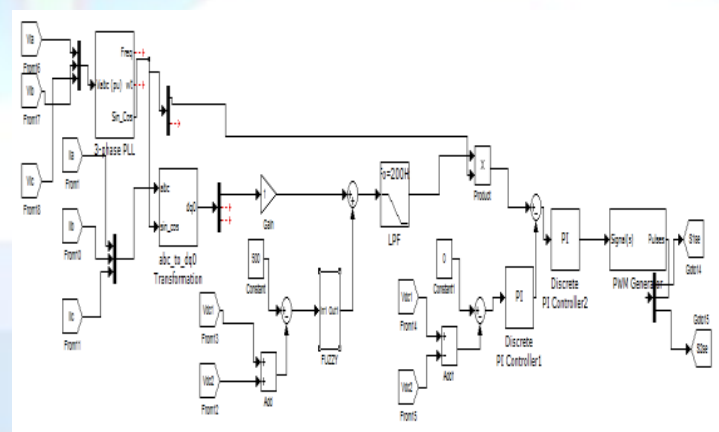

Fig. 14: Series PWM inverter

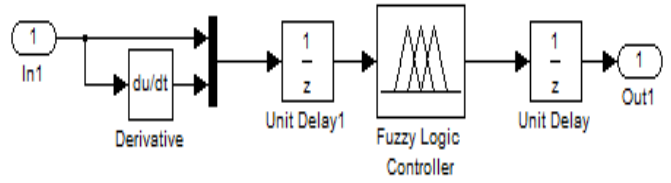

Fig15: Fuzzy logic controller

SIMULATION RESULTS: 


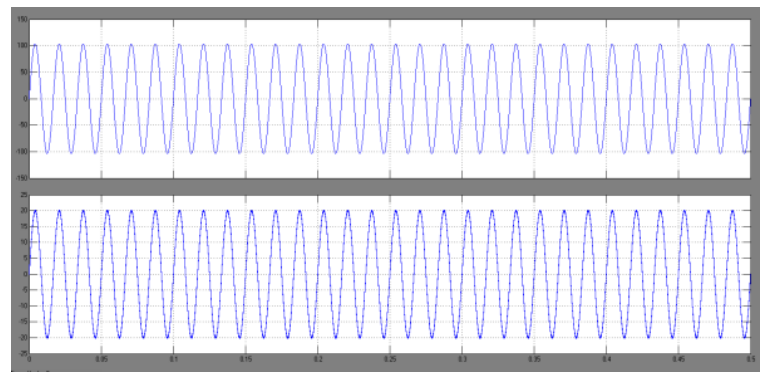

Fig16: Source Voltage and current

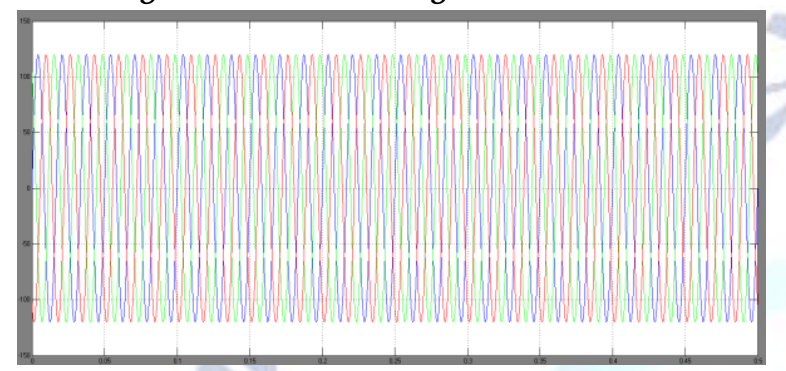

Fig17: Inverter inductor 3-phase voltages

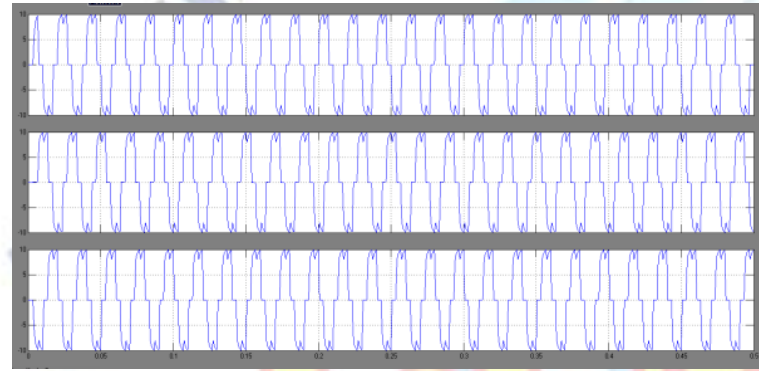

Fig18: Inverter inductor 3-phase Currents

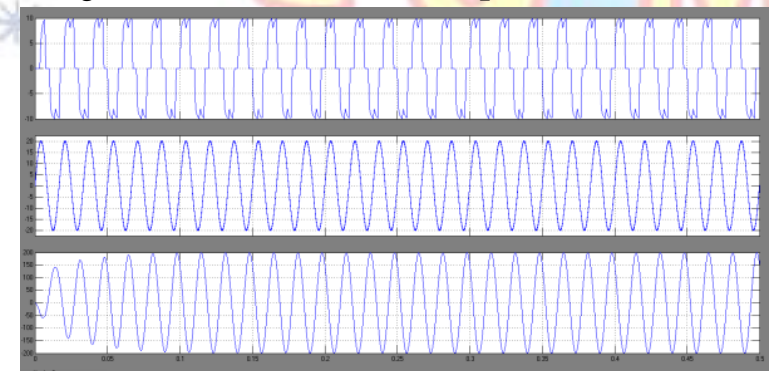

Fig19: (a): Inverter current, (b): Source current (c): parallel converter cpa

\section{CONCLUSION}

This paper exhibited the investigation and the trial approval of a neighborhood three-stage four-wire control dispersion framework. The framework, showed for applications in country or remote territories where three-stage dissemination lattices are not available, was considered dependent on bound together power quality conditioner functionalities. With sequential and parallel separating capacity, two inverter topologies were utilized to create the UPQC-1Ph-to-3Ph. Along these lines, the single-stage arrangement converter was conveyed utilizing a half-connect inverter, while the three-stage parallel converter was executed utilizing a 3-Leg split capacitor inverter.
Utilizing the double pay technique, the proposed framework was capable of sustaining direct and non-straight three-stage loads acting with widespread dynamic separating ability, i.e., going about as SAPF and PAPF.

FUTURE SCOPE: The Fuzzy based Sliding Mode Control based System upgrades the dependability of the framework and enhances the dynamic reaction of the framework working in flawed conditions betterly and it has additionally adequately improved the damping of electromechanical motions as per non-straight recreation results.

\section{REFERENCES}

[1] V. khadkikar and A. Chandra, "A tale structure for three-stage fourwire dissemination framework using bound together power quality conditioner(UPQC)," IEEE Transaction on industry application ,Vol.45,no.5,pp.1897-1902,Sep/oct.2009.

[2] Y. Buddy, A. Swarup, and B. Singh, "A relative examination of threephase four-wire UPQC topologies, "Power Electronics, Drives and Energy Systems (PEDES) and 2010 Power India, 2010 Joint International Conference on, On page(s): 1 - 6, Vol. 20-23 Dec. 2010.

[3] M. Aredes, R. M. Fernandes, "A brought together power quality conditioner with voltage SAG/SWELL remuneration capacity," Power Electronics Conference, 2009. COBEP '09. Brazilian, On page(s): 218 - 224, Vol, Sept. 27 2009-Oct. 1 2009.

[4] M. Aredes, K. Heumann, and E. H. Watanabe, "A widespread dynamic electrical cable conditioner," IEEE Trans. control Del., vol.13, no.2, pp.542-551, Apri.1998.

[5] G. Chen, Y. Chen, and K. M. Smedley, "Three-stage four-leg dynamic power quality conditioner without references figuring," in Proc. nineteenth IEEE APEC, 2004, vol. 1, pp. 829- 836.

[6] A. Elnady, M. M. A. Salama, "Bound together methodology for moderating voltage droop and voltage flash utilizing the DSTATCOM,"IEEE Trans. Power Delivery, vol.20, pp.992-1000, April 2005.

[7] J. Puga and J. Ferreira, "Arrangement shunt control dynamic channel for high infiltration of installed generation one powerful methodology," Industrial Electronics (ISIE), 2010 IEEE International Symposium on, On page(s): 2587 2592, Vol. 4-7 July 2010.

[8] J. Ferreira, "Arrangement shunt control dynamic channel for high entrance of implanted generation one powerful methodology," Industrial Electronics (ISIE), 2010 IEEE International Symposium on, On page(s): 2587 - 2592, Vol. 4-7 July 2010.

[9] A. b. Hamadi, K. Al-Haddad, and R. Rahmani, "Arrangement dynamic channel to alleviate control quality for medium size mechanical burdens," IEEE Int. Conf. onlnd. Electron. 2006, vol.2, pp.15-101515.

[10] M. T. Haque, "Single-stage PQ hypothesis," in Proc. 33rd IEEE PESC, 2002, vol. 4, pp. 1815- 1820. 